\title{
Lower Ionospheric Turbulence Variations during the Intense Tectonic Activity of October, 2018 at Zakynthos Area, Greece
}

\author{
Michael E. Contadakis ${ }^{1}$, Dimitrios N. Arabelos ${ }^{1}$, George S. Vergos ${ }^{1}$, Emmanuel M. Scordilis ${ }^{2}$ \\ ${ }^{1}$ Department of Geodesy and Surveying, Aristotle University of Thessaloniki, Thessaloniki, Greece \\ ${ }^{2}$ Department of Geophysics, Aristotle University of Thessaloniki, Thessaloniki, Greece \\ Email: kodadaki@eng.auth.gr
}

How to cite this paper: Contadakis, M.E., Arabelos, D.N., Vergos, G.S. and Scordilis , E.M. (2019) Lower Ionospheric Turbulence Variations during the Intense Tectonic Activity of October, 2018 at Zakynthos Area, Greece. Open Journal of Earthquake Research, 8, 255-266.

https://doi.org/10.4236/ojer.2019.84015

Received: October 17, 2019

Accepted: November 8, 2019

Published: November 11, 2019

Copyright $\odot 2019$ by author(s) and Scientific Research Publishing Inc. This work is licensed under the Creative Commons Attribution International License (CC BY 4.0).

http://creativecommons.org/licenses/by/4.0/

\begin{abstract}
In this paper we investigate the ionospheric turbulence from TEC observations before and during the intense seismic activity of October of 2018 at Zakynthos area $\left(\lambda=20.51^{\circ} \mathrm{E}, \varphi=37^{\circ} 34^{\prime} \mathrm{N}\right)$, (Main shock: ML 6.6, $60.6 \mathrm{~km} \mathrm{SW}$ of Zakynthos). The Total Electron Content (TEC) data of 5 Global Positioning System (GPS) stations of the EUREF network, which are being provided by IONOLAB (Turkey), were analyzed using Discrete Fourier Analysis in order to investigate the TEC variations. The results of this investigation indicate that the High-Frequency limit $f_{o}$, of the ionospheric turbulence band content, increases as the site and the moment of the earthquake occurrence are approaching, pointing to the earthquake locus. We conclude that the LAIC mechanism through acoustic or gravity wave could explain this phenomenology.
\end{abstract}

\section{Keywords}

Seismicity, Lower Ionosphere, Ionospheric Turbulence, Brownian Walk

\section{Introduction}

It is generally accepted that the original cause of the earth surface perturbation is the increasing stress and the rapture of the rocks at the earthquake preparation area where radon release takes place. The coupling of radon with the atmosphere at the earth surface results in the increase of the Ionization, Temperature [1], Electromagnetic field and disturbances in the air electrical conductivity. This perturbation is transmitted to the Ionosphere by some LAIC Mechanism. The proposed possible hypothesis on the mechanism of coupling between lithospheric activity and ionosphere is Transmission through the: 1) Chemical chan- 
nels [2], 2) Atmospheric oscillation (or acoustic) channels [3] and (3) Electromagnetic channels [2] [3]. Finally, a hypothesis of electrostatic channel has been proposed by Freund [4] on the basis of positive hole charge carriers release in crustal rocks, alongside electrons. When the positive holes arrive at the Earth's surface, they can cause massive ionization of the air molecules and positive surface potential. Subsequently, these perturbations are transmitted to Ionosphere. From all these hypothesis for the LAIC mechanism, we believe that the hypothesis of the Atmospheric oscillation (or acoustic) channel [3] is the most suitable for the explanation of our observations so far [5] [6] [7], since the observed frequency band of the suggested Gravity waves of our work complies with the observed frequency bands of the Internal Atmospheric Gravity waves (Acoustic standing waves) by Horie et al. [8] and Molchanov et al. [9] [10]. Thus according to the LAIC mechanism through Acoustic channel, Acoustic or Gravity waves affect the turbulence of the lower ionosphere. Subsequently the produced disturbance starts to propagate in the ionosphere's waveguide as gravity wave. The inherent frequencies of the acoustic or gravity wave range between $0.003 \mathrm{~Hz}$ (period $5 \mathrm{~min}$ ) and $0.0002 \mathrm{~Hz}$ (period $83 \mathrm{~min}$ ), which according to Molchanov et al. [9] [10] correspond to the frequencies of the turbulent produced by tectonic activity during the earthquake preparation period. During this propagation, the higher frequencies are progressively damped. Thus, observing the frequency content of the ionospheric turbidity we will observe a decrease of the higher limit of the turbidity frequency band. Our investigations so far, on the occasion of strong earthquakes approve this view. Never the less, since the approval of the theoretical view depends mainly on the compliance of the observational results to the theoretical clues, further observational results are always welcome.

In this paper we investigate the ionospheric turbulence from TEC observations before and during the intense seismic activity of October of 2018 at Zakynthos area $\left(\lambda=20.51^{\circ} \mathrm{E}, \varphi=37^{\circ} 34^{\prime} \mathrm{N}\right.$ ), (Main shock: ML 6.6, $60.6 \mathrm{~km} \mathrm{SW}$ of Zakynthos). The Total Electron Content (TEC) data of 5 Global Positioning System (GPS) stations of the EUREF network, which are being provided by IONOLAB (Turkey), were analyzed using Discrete Fourier Analysis in order to investigate the TEC variations [2] [3] [4].

\section{Seismotectonic Information}

On October 26, $2018\left(22: 54\right.$ GMT) a strong $\left(\mathrm{M}_{\mathrm{L}}=6.6\right)$ shallow $(\mathrm{h} \sim 10 \mathrm{~km})$ earthquake occurred $\sim 50 \mathrm{~km}$ off the SW coast of Zakynthos Island, southern Greece $\left(37.34^{\circ} \mathrm{N}, 20.51^{\circ} \mathrm{E}\right)$. The main shock was followed by an aftershock sequence that lasted for almost three months.

Strong earthquakes have occurred in the broader region in the past with magnitudes up to 7.2 (Table 1, Figure 1). Their generation is related to significant regional seismic faults, characterizing the NW edge of the Hellenic Trench and showing dextral strike slip faulting with thrust component (typical fault plane solution: $\mathrm{Az}=38$, Dip $=61$, Rake $=174 ;[11])$. However, remarkable thrust 


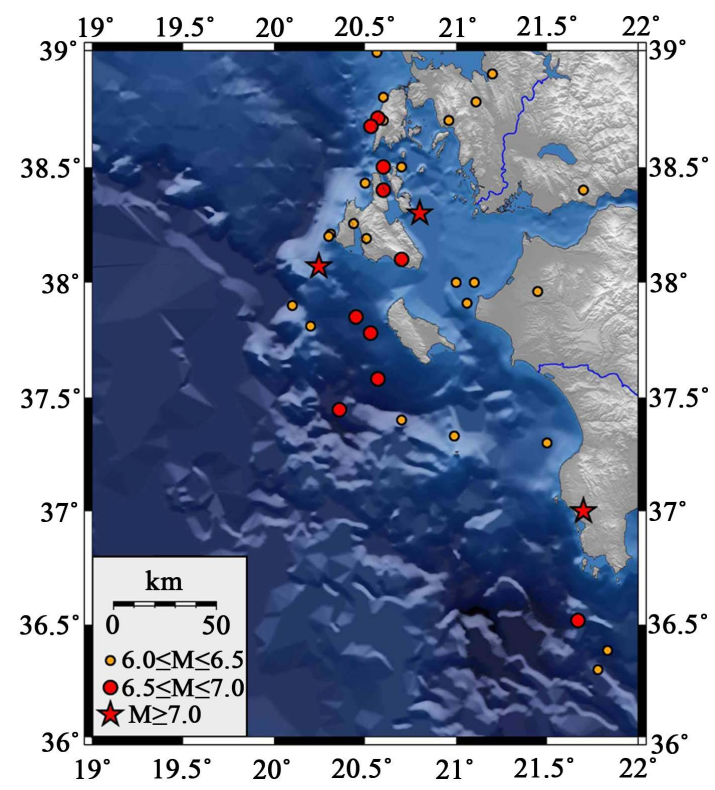

Figure 1. Epicenters of all known strong $(M \geq 6.0)$ earthquakes that occurred in the wider region since 1900 (see Table 1). http://www.isc.ac.uk/.

Table 1. All known strong $(M \geq 6.5)$ shallow $(h<60 \mathrm{~km})$ earthquakes that occurred since 1900 in the broader region of the seismic sequence under study (Information from Papazachos and Papazachou, 2003 and from the online bulletin of ISC, http://www.isc.ac.uk/).

\begin{tabular}{cccccc}
\hline Year & MoDa & Hr:Mn:Sec & Lat $^{\circ} \mathbf{N}$ & Lon $^{\circ} \mathrm{E}$ & $\mathrm{M}$ \\
\hline 1912 & 0124 & $16: 22: 51$ & 38.1000 & 20.7000 & 6.8 \\
1915 & 0127 & $01: 09: 59$ & 38.4000 & 20.6000 & 6.6 \\
1915 & 0807 & $15: 04: 03$ & 38.5000 & 20.6000 & 6.7 \\
1947 & 1006 & $19: 55: 34$ & 37.0000 & 21.7000 & 7.0 \\
1948 & 0422 & $10: 42: 45$ & 38.7100 & 20.5700 & 6.5 \\
1953 & 0811 & $03: 32: 22$ & 37.8500 & 20.4500 & 6.8 \\
1953 & 0812 & $09: 23: 52$ & 38.3000 & 20.8000 & 7.2 \\
1959 & 1115 & $17: 08: 43$ & 37.7800 & 20.5300 & 6.8 \\
1976 & 0511 & $16: 59: 44$ & 37.4453 & 20.3591 & 6.5 \\
1983 & 0117 & $12: 41: 30$ & 38.0702 & 20.2457 & 7.0 \\
1997 & 1118 & $13: 07: 41$ & 37.5800 & 20.5700 & 6.6 \\
2008 & 0214 & $10: 09: 23$ & 36.5173 & 21.6699 & 6.8 \\
2015 & 1117 & $07: 10: 08$ & 38.6751 & 20.5320 & 6.5 \\
\hline
\end{tabular}

faults, striking NW-SE are also met in the same region (to the SW of Zakynthos Island) with typical fault plane solution: $\mathrm{Az}=309$, Dip $=23$, Rake $=101$ [11]. The fault plane solution of the main shock of October (the two nodal planes, NP1 and NP2, according to GCMT, have Az $=13^{\circ}$, Dip $=24^{\circ}$, Rake $=165^{\circ}$ and $\mathrm{Az}=117^{\circ}, \mathrm{Dip}=84^{\circ}$, Rake $=66^{\circ}$, respectively;

https://www.globalcmt.org/CMTsearch.html), assumes that both the above 
seismic faults could be responsible for its generation.

The main shock was followed by a remarkable number of aftershocks, the strongest of which occurred four days later (on October 30, 15:12 GMT) with $\mathrm{M}_{\mathrm{L}}$ $=5.4$, while within the same day and a few hours earlier (02:59 GMT), another strong aftershock with similar magnitude $\left(M_{L}=5.3\right)$ occurred, with its epicenter very close to that of the main shock. Table 2 and the map of Figure 2 give information on the aftershock activity during the first four months after the occurrence of the main shock.

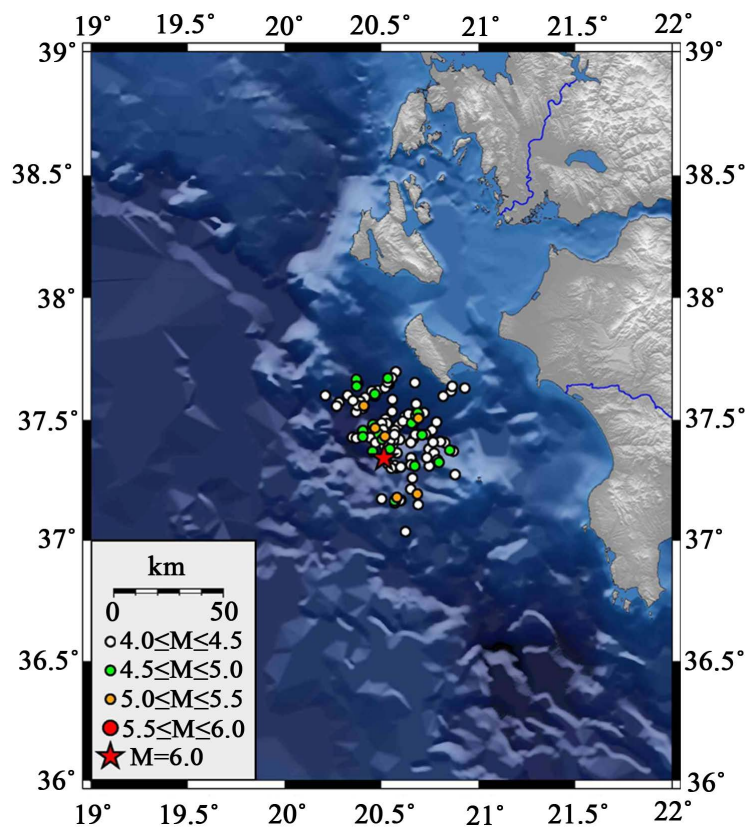

Figure 2. Seismic activity SE of Zakynthos Isl. (southern Greece) during the period October 25, 2018-February 28, 2019. Red star denotes the epicenter of the main shock (October 25, 2018; 22:54 UTC; $\mathrm{M}_{\mathrm{L}}=6.6$ ). (Data from:

http://geophysics.geo.auth.gr/the seisnet/WEBSITE 2005/catalogs en.html, http://www.gein.noa.gr/services/current catalogue.php and http://bbnet.gein.noa.gr/HL/seismicity/catalogues/real-time-catalogue.

Table 2. A list of the strongest $(M \geq 5.0)$ earthquakes which occured in the broader area of Zakynthos around the time of the main shock occurence (Information from http://geophysics.geo.auth.gr/ss/bulletins.html and http://bbnet.gein.noa.gr/HL/seismicity/catalogues/real-time-catalogue).

\begin{tabular}{ccccccc}
\hline & Origin Time (GMT) & Location & $\begin{array}{c}\text { Latitude } \\
\left({ }^{\circ} \mathrm{N}\right)\end{array}$ & $\begin{array}{c}\text { Longitude } \\
\left({ }^{\circ} \mathrm{E}\right)\end{array}$ & $\begin{array}{c}\text { Depth } \\
(\mathrm{km})\end{array}$ & ML \\
\hline 1 & $2018 / 08 / 31$ 07:12:24 & $26.5 \mathrm{~km}$ WSW of Karditsa & 39.29 & 21.63 & 10 & 5.0 \\
2 & $2018 / 09 / 2710: 21: 50$ & $28.4 \mathrm{~km} \mathrm{SW}$ of Methoni & 36.64 & 21.47 & 4 & 5.1 \\
3 & $2018 / 10 / 2522: 54: 49$ & $60.6 \mathrm{~km} \mathrm{SW}$ of Zakynthos & 37.34 & 20.51 & 10 & 6.6 \\
4 & $2018 / 10 / 2523: 09: 20$ & $79.0 \mathrm{~km}$ SSW of Zakynthos & 37.11 & 20.64 & 3 & 5.1 \\
5 & $2018 / 10 / 3002: 59: 59$ & $40.6 \mathrm{~km}$ WSW of Zakynthos & 37.59 & 20.51 & 7 & 5.4 \\
6 & $2018 / 10 / 3015: 12: 02$ & $53.8 \mathrm{~km} \mathrm{SW}$ of Zakynthos & 37.46 & 20.45 & 6 & 5.5 \\
\hline
\end{tabular}




\section{TEC Variation over Mid Latitude in Europe}

In the following we investigate the variations of TEC [2] [12] over the broader area of Mediterranean before and during the intense seismic activity of October, 2018 at Zakynthos area $\left(\lambda=20.51^{\circ} \mathrm{E}, \varphi=37^{\circ} 34^{\prime} \mathrm{N}\right.$ ), (Main shock: ML 6.6, 60.6 $\mathrm{km}$ SW of Zakynthos). To this purpose we use the TEC estimates provided by IONOLAB (http://www.ionolab.org) [13] (Arikan et al. 2009) for 5 mid latitude GPS stations of EUREF which cover epicentre distances from the active areas ranging from $496.7 \mathrm{~km}$ to $2164.3 \mathrm{~km}$, for the time periods between 15/07/2018 to $15 / 11 / 2018$. The selected GPS stations have about the same latitude and are expected to be affected equally from the Equatorial Anomaly as well as from the Auroral storms. Table 3 displays the 5 EUREF stations while Figure 3 displays the locus of the five GPS stations and the main shocks.

IONOLAB system provides comparison graphs of its TEC estimations with the estimations of the other TEC providers of IGS in its site. In this work only TEC estimations in perfect accordance among all providers were used. The TEC values are given in the form of a Time Series with a sampling gap of 2.5 minute. The IONOLAB TEC estimation system uses a single station receiver bias estimation algorithm, IONOLAB-BIAS, to obtain daily and monthly averages of receiver bias and is successfully applied to both quiet and disturbed days of the ionosphere for station position at any latitude. In addition, TEC estimations with high resolution are also possible [13]. Figure 4 display the TEC variation over the 5 EUREF stations for the time periods between 25/09/2018 to $25 / 11 / 2018$.

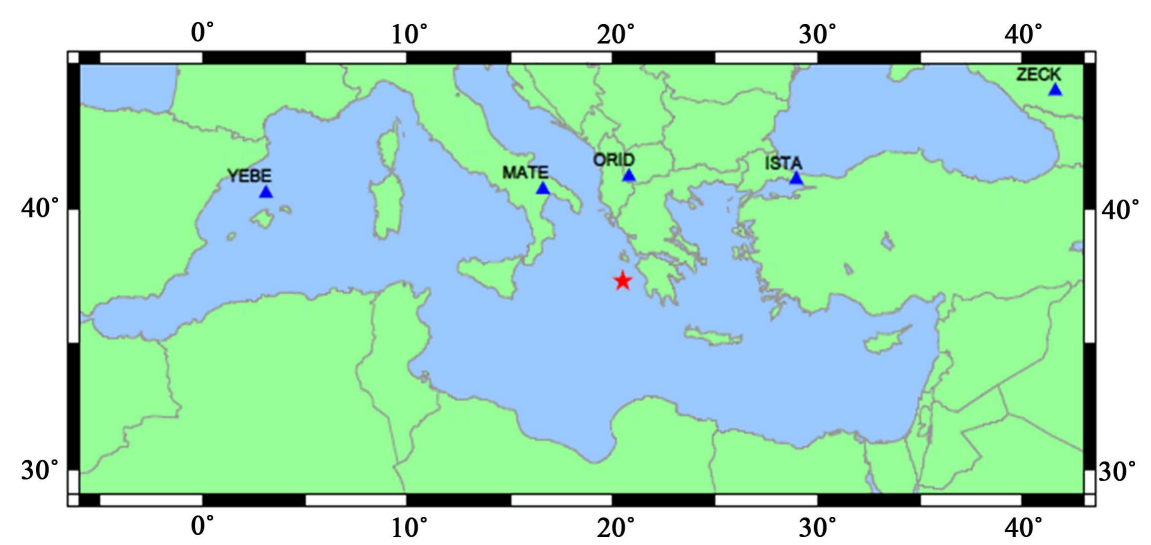

Figure 3. The locus of the five GPS stations and the main shocks.

Table 3. Distance of GPS stations from the epicenter of the earthquake.

\begin{tabular}{cccc}
\hline GPS Site & Latitude Degree & Longitude Degree & Epicentral Distance $(\mathrm{km})$ \\
\hline Yebes & 40.52000 & -3.08860 & 2067.23 \\
Matera & 40.667267 & 16.604712 & 500.65 \\
Ohrid & 41.123657 & 20.801771 & 421.50 \\
Istambul & 41.010000 & 28.960278 & 839.28 \\
Zelenchukskaya & 43.857071 & 41.585293 & 1921.02 \\
\hline
\end{tabular}




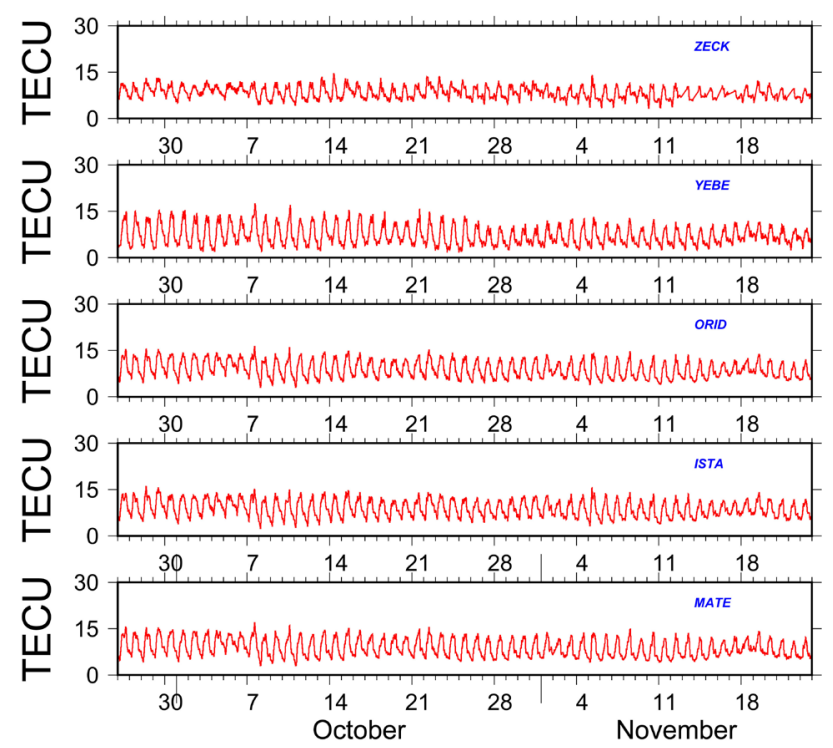

Figure 4. The TEC variation over the 5 EUREF stations for the time period between $25 / 09 / 2018$ to $25 / 11 / 2018$.

\section{Fast Fourier Transform Analysis}

The Power Spectrum of TEC variations will provide information on the frequency content of them. Apart of the well known and well expressed tidal variations, for which the reliability of their identification can be easily inferred by statistical tests, small amplitude space-temporal transient variations cannot have any reliable identification by means of a statistical test. Nevertheless looking at the logarithmic power spectrum we can recognize from the slope of the diagram whether the contributed variations to the spectrum are random or periodical. If they are random the slope will be 0 , which correspond to the white noise, or -2 which correspond to the Brownian walk noise, otherwise the slope will be different, the so called Fractal Brownian walk [14]. This means that we can trace the presence of periodical variations in the logarithmic power spectrum of TEC variations. As an example, Figure 5 displays the logarithmic power spectrum of TEC variations over the GPS station of Mate at the days of 23 to 25/10/2018. It is seen that the slope of the diagram up to the $\log (\mathrm{f})=-2.2$, is -2 . This means that for higher frequencies the TEC variation is random noise. On the contrary the variation of TEC for lower frequencies contains not random variations i.e. turbulent. So we conclude that the upper frequency limit fo of the turbulent band is $738.6 \mu \mathrm{Hz}$. Or, equivalently, the lower period limit Po of the contained turbulent is 22.563 minutes.

\section{Results and Discussion}

Figure 6 and Figure 7 display the variation with epicentral distance of TEC turbulence frequency band upper limit $\mathrm{f}_{\mathrm{o}}$ and of lower Period limit $\mathrm{P}_{\mathrm{o}}$, respectively, over the selected EUREF GPS stations for the day of the shocks, i.e. 25 of Oktober, 2018 and for a seismically "quiet" day, the 8 of November 2018. It is 


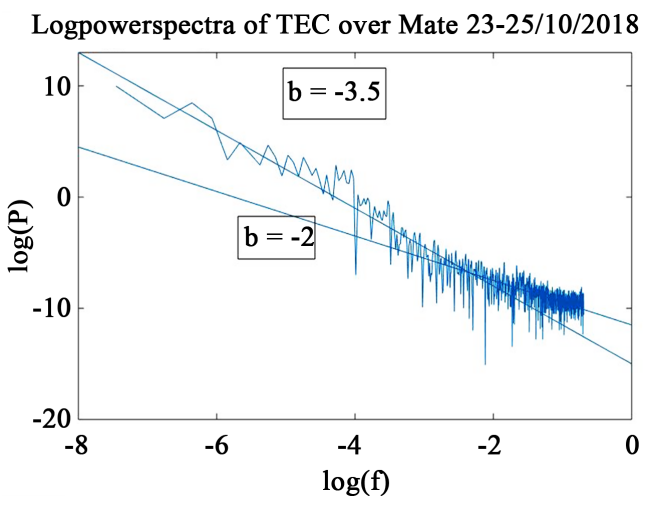

Figure 5. The logarithmic power spectrum of TEC variations over the GPS station of Mate around the days of $23-25 / 10 / 2018$. Where $\log (\mathrm{f})$ is the logarithm of the turbulent frequency and $\log (\mathrm{P})$ is the logarithm of the Power spectrum density.

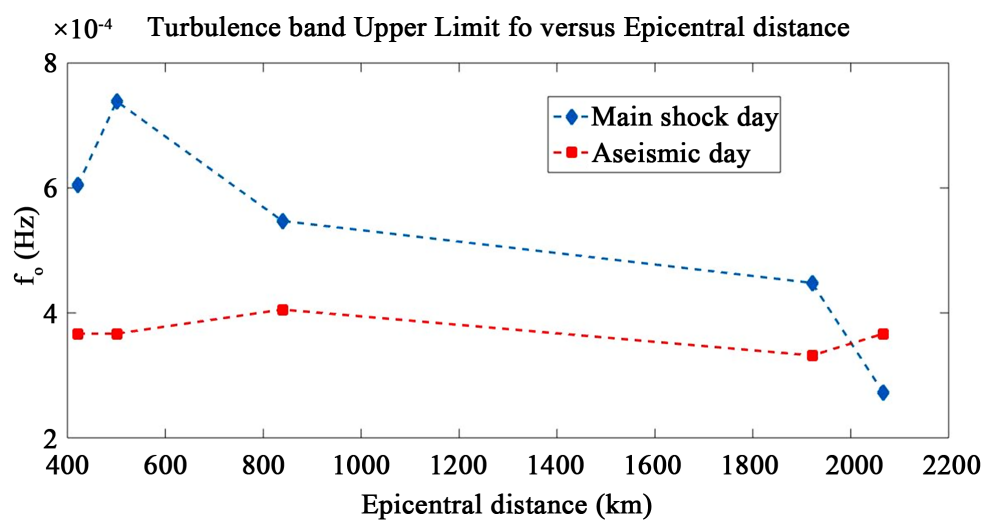

Figure 6. Variation of TEC turbulence frequency upper limit $f_{o}$ over the GPS Stations with the epicentral distance, at 25/10/2018 i.e. the day of the main earthquake (blue) and at $08 / 11 / 2018$, an aseismic day.

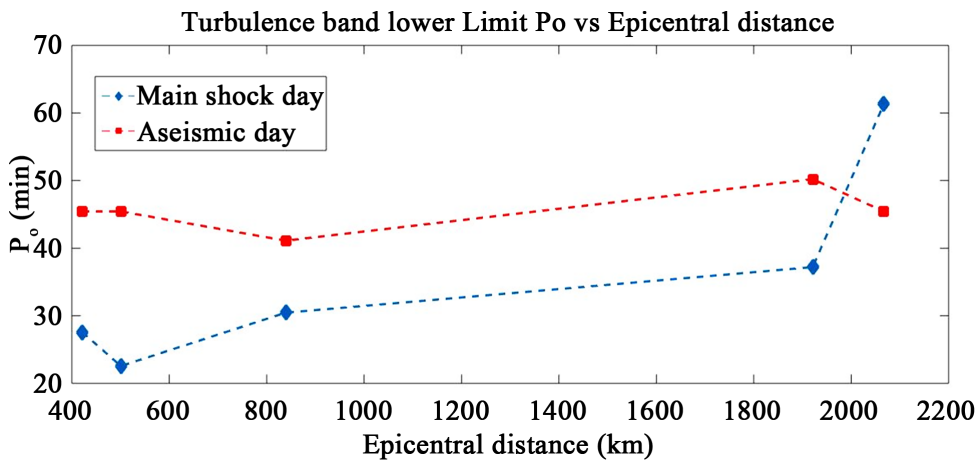

Figure 7. Variation of TEC turbulence Period lower limit Po over the GPS Stations with the epicentral distance, at 25/10/2018 i.e. the day of the main earthquake (blue) and at $08 / 11 / 2018$, an aseismic day (red).

shown that at the day of the earthquake a strong dependence of the upper frequency $f_{o}$ (lower period $P_{o}$ ) limit of the Ionospheric turbulent content with the epicentral distance is observed. In particular, the closer of the GPS station to the active area the higher frequency $f_{0} /$ lower period $P_{o}$ limit is. This dependence 
is not shown at the "quiet" day. As it is seen from Figure 6 and Figure 7, the upper frequency limit, $\mathrm{f}_{\mathrm{o}}$, and lower period limit, $\mathrm{P}_{\mathrm{o}}$, of the turbulence band in quiet days, or at remote GPS stations during the days of seismic activity, range between $400-200 \mu \mathrm{Hz}$ or equivalently $41.5-83 \mathrm{~min}$. A brief statistic of our data for the quiet days give mean values: Mean $\left(\mathrm{f}_{\mathrm{o}}\right)=372.7 \pm 75 \mu \mathrm{Hz}$ and Mean $\left(\mathrm{P}_{\mathrm{o}}\right)=$ $44.71 \pm 8.25 \mathrm{~min}$. These frequencies are in the range of the observed Acoustic Gravity Waves on the occasions of strong earthquakes, which are: periods of 30 to $100 \mathrm{~min}$ [9] [10] or 20 to $80 \mathrm{~min}$ [8].

Figure 8 and Figure 9 show the variation of the upper frequency $f_{o}$ and of the lower period $\mathrm{P}_{\mathrm{o}}$, limits of ionospheric turbulence content over the nearest to the active area Orid GPS station while Figure 10 and Figure 11 show the variation of the upper frequency $f_{o}$ and of the lower period $P_{o}$, limits of ionospheric turbulence content over the most remote to the active area Yebes GPS station. In the same figures the occurrence times of strong earthquakes $(M>5.0)$ are shown with arrows. It is seen that at the days of strong earthquakes the ionospheric turbulence upper frequency limit, $\mathrm{f}_{\mathrm{o}}$, increases (or the lower period limit, $\mathrm{P}_{\mathrm{o}}$, decreases). These results indicate time and space convergence of increasing turbulence frequency band upper limit $\mathrm{f}_{\mathrm{o}}$ to the earthquakes occurrence.

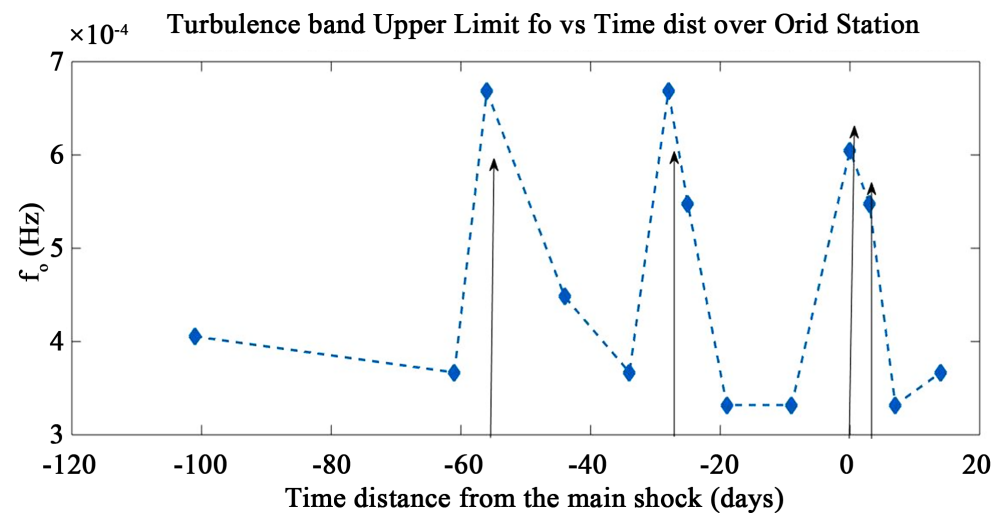

Figure 8. Variation of TEC turbulence frequency upper limit $f_{o}$ over the GPS Station of Orid, with the epicentral distance.

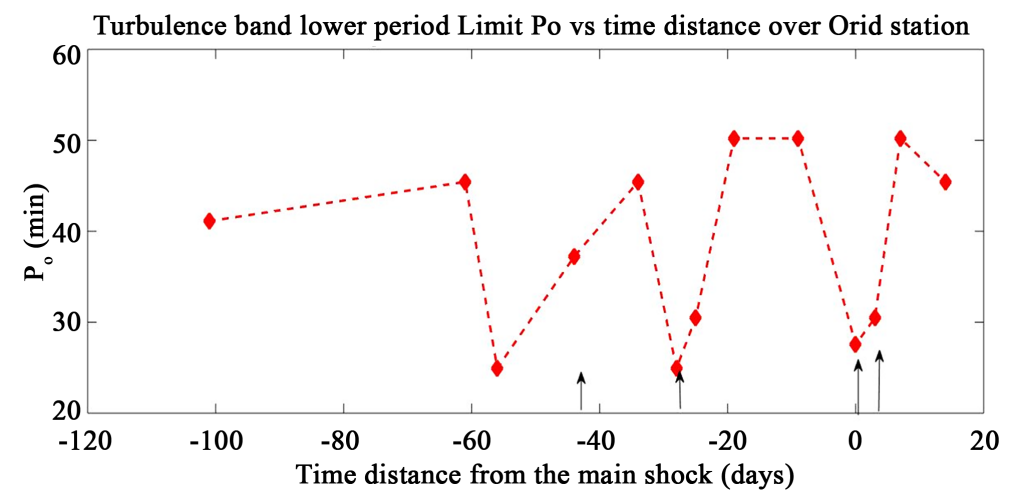

Figure 9. Variation of TEC turbulence Period lower limit over the GPS Station of Orid. The arrows show the occurrence of strong earthquakes $(M>5.0)$. 


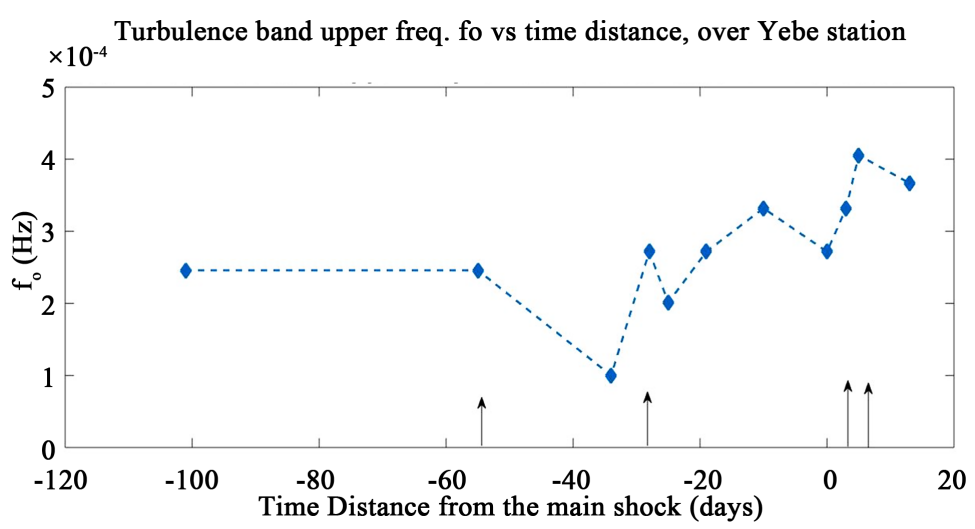

Figure 10. Variation of TEC turbulence frequency upper limit over the GPS Station of Yebes, with the epicentral distance. The arrows show the occurrence of strong earthquakes $(\mathrm{M}>5.0)$.

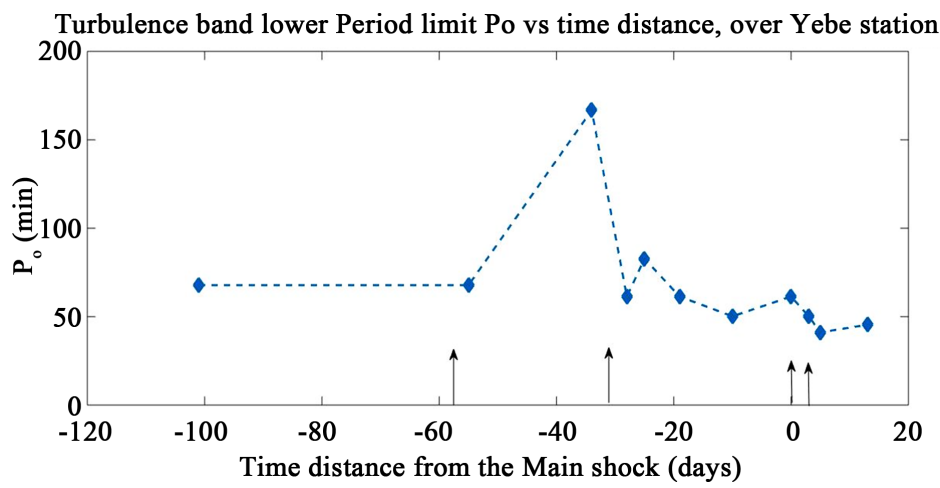

Figure 11. Variation of TEC turbulence Period lower limit over the GPS Station of Yebes, with the epicentral distance. The arrows show the occurrence of strong earthquakes $(M>$ $5.0)$.

Hobara et al. [15] in a study on the ionospheric turbulence in low latitudes concluded that the attribution of the turbulence to earthquake process and not to other sources, i.e. solar activity, storms etc. is not conclusive. Nevertheless in our case, the steady monotonic, time and space, convergence of the frequency band upper limit $f_{o}$ increment, to the occurrence of the East Aegean strong earthquakes is a strong indication that the observed turbulence is generated by the respective earthquakes preparation processes.

The qualitative explanation of this phenomenology can be offered on the basis of the LAIC: Tectonic activity during the earthquake preparation period produces anomalies at the ground level which propagate upwards in the troposphere as Acoustic or Standing gravity waves [16] [17]. These Acoustic or Gravity Waves affect the turbulence of the lower ionosphere, where sporadic Es-layers may appear too [18], and the turbulence of the F layer. Subsequently, the produced disturbance starts to propagate in the ionosphere's waveguide as gravity wave and the inherent frequencies of the acoustic or gravity waves can be traced on TEC variations [i.e. the frequencies between $0.003 \mathrm{~Hz}$ (period $5 \mathrm{~min}$ ) and $0.0002 \mathrm{~Hz}$ (period $100 \mathrm{~min}$ )], which, according to Molchanov et al. [9] [10] and 
Horie et al. [8] correspond to the frequencies of the turbulent induced by the LAIC coupling process to the ionosphere. As we move far from the disturbed point, in time or in space, the higher frequencies (shorter wavelength) variations are progressively attenuated. It has to be noted that the original cause of the earth surface perturbation is the increasing stress and the rapture of the rocks at the earthquake preparation area where radon release takes place. The coupling of radon with atmosphere at the earth's surface results to the increase the ionization, temperature [1], electromagnetic field and to disturbances in the air electrical conductivity. This perturbation is transmitted to the Ionosphere by some LAIC Mechanism. The proposed possible hypothesis on the mechanism of coupling between lithospheric activity and ionosphere is transmission through the: 1) chemical channels [2], 2) atmospheric oscillation (or acoustic) channels [3] and 3) electromagnetic channels [2] [3]. Finally, a hypothesis of electrostatic channel has been proposed by Freund [4] on the basis of positive hole charge carriers release in crustal rocks, alongside electrons. When the positive holes arrive at the Earth's surface, they can cause massive ionization of the air molecules and positive surface potential. Subsequently these perturbations are transmitted to Ionosphere. From this hypothesis for the LAIC mechanism, we believe that the hypothesis of the atmospheric oscillation (or acoustic) channel [3] is most suitable for the explanation of our observations, since the observed frequency band of the suggested gravity waves of this work comply with the observed frequency bands of the Internal Atmospheric Gravity waves (Acoustic standing waves) by Horie et al. [8] and Molchanov et al. [9] [10], as it is already mentioned.

\section{Conclusion}

The results of our investigation, on the case of the recent East Aegean tectonic activity, indicate that the High-Frequency limit $\mathrm{f}_{\mathrm{o}}$, of the ionospheric turbulence content, increases as we are getting closer to the site and the time of the earthquake occurrence, pointing to the earthquake location. We conclude that the LAIC mechanism through acoustic or gravity wave could explain this phenomenology. That is, tectonic activity during the earthquake preparation period produces anomalies at the ground level which propagate upwards in the troposphere as Acoustic or Standing gravity waves. These Acoustic or Gravity waves affect the turbulence of the lower ionosphere, where sporadic Es-layers may appear, too, as well as the turbulence of the F layer. Subsequently, the produced disturbance starts to propagate in the ionosphere's wave guide. Thus observing the frequency content of the ionospheric turbulence we will observe a decrease of the higher limit of the turbulence frequency band, as a result of the differential frequency attenuation of the propagating waves.

\section{Conflicts of Interest}

The authors declare no conflicts of interest regarding the publication of this paper. 


\section{References}

[1] Tramutoli, V., Genzano, N., Lisi, M. and Pergola N. (2018) Significant Cases of Preseismic Thermal Infrared Anomalies. In: Ouzounov, D., et al., Eds., Pre-Earthquake Processes. A Multidisciplinary Approach to Earthquake Prediction Studies, AGU Book, Wiley, New York, 301-338. https://doi.org/10.1002/9781119156949.ch19

[2] Pulinet, S.S., Ouzounov, D., Karelin, A. and Davidenko D. (2018) Lithosphere-Atmosphere-Ionosphere-Magnetosphere Coupling-A Concept for Pre-Earthquake Signals Generation. In: Ouzounov, D., et al., Eds., Pre-Earthquake Processes. A Multidisciplinary Approach to Earthquake Prediction Studies, AGU Book, Wiley, New York, 79-99. https://doi.org/10.1002/9781119156949.ch6

[3] Hayakawa, M., Asano, T., Rozhnoi, A. and Solovieva, M. (2018) Very-Low- and Low-Frequency Sounding of Ionospheric Perturbations and Possible Association with Earthquakes. In: Ouzounov, D., et al., Eds., Pre-Earthquake Processes. A Multidisciplinary Approach to Earthquake Prediction Studies, AGU Book, Wiley, New York, 277-304. https://doi.org/10.1002/9781119156949.ch16

[4] Freund, F.T. (2009) Stress-Activated Positive Hole Carriers in Rocks and the Generation of Pre-Earthquake Signals. In: Hayakawa, M., Ed., Electromagnetic Phenomena Associated with Earthquakes, Transworld Research Network, Trivandrum, India, 41-96.

[5] Contadakis, M.E., Arabelos, D.N., Asteriadis, G., Spatalas, S.D. and Pikridas, C. (2008) TEC Variations over the Mediterranean during the Seismic Activity Period of the Last Quarter of 2005 in the Area of Greece. Natural Hazards and Earth System Sciences, 8, 1267-1276. https://doi.org/10.5194/nhess-8-1267-2008

[6] Contadakis, M.E., Arabelos, D.N., Asteriadis, G., Spatalas, S.D. and Pikridas, C. (2012) TEC Variations over Southern Europe before and during the M6.3 Abruzzo Earthquake of 6th April 2009. Annals of Geophysics, 55, 83-93.

[7] Contadakis, M.E., Arabelos, D.N., Vergos, G., Spatalas, S.D. and Skordilis, M. (2015) TEC variations over the Mediterranean before and during the strong earthquake $(\mathrm{M}=6.5)$ of 12th October 2013 in Crete, Greece. Physics and Chemistry of the Earth, 85, 9-16. https://doi.org/10.1016/j.pce.2015.03.010

[8] Horie, T., Maekawa, S., Yamauchi, T. and Hayakawa, M. (2007) A Possible Effect of Ionospheric Perturbations Associated with the Sumatra Earthquake, as Revealed from Subionospheric Very-Low-Frequency (VLF) Propagation (NWC-Japan). International Journal of Remote Sensing, 28, 3133-3139.

https://doi.org/10.1080/01431160601094476

[9] Molchanov, O., Biagi, P.F., Hayakawa, M., Lutikov, A., Yunga, S., Iudin, D., Andreevsky, S., Rozhnoi, A., Surkov, V., Chebrov, V., Gordeev, E., Schekotov, A. and Fedorov, E. (2004) Lithosphere-Atmosphere-Ionosphere Coupling as Governing Mechanism for Preseismic Short-Term Events in Atmosphere and Ionosphere. Natural Hazards and Earth System Sciences, 4, 757-767. https://doi.org/10.5194/nhess-4-757-2004

[10] Molchanov, O., Schekotov, A., Solovieva, M., Fedorov, E., Gladyshev, V., Gordeev, E., Chebrov, V., Saltykov, D., Sinitsin, V.I., Hattori, K. and Hayakawa, M. (2005) Near Seismic Effects in ULF Fields and Seismo-Acoustic Emission: Statistics and Explanation. Natural Hazards and Earth System Sciences, 5, 1-10. https://doi.org/10.5194/nhess-5-1-2005

[11] Papazachos, B.C. and Papazachou, C.B. (2003) The Earthquakes of Greece. Ziti Publications, Thessaloniki, 273 p. (In Greek) 
[12] Liu, J.-Y., Hattori, K. and Chen, Y.-I. (2018) Application of Total Electron Content Derived from the Global Navigation Satellite System for Detecting Earthquake Precursors. In: by Ouzounov, D., et al., Eds., Pre-Earthquake Processes. A Multidisciplinary Approach to Earthquake Prediction Studies, AGU Book, Wiley, New York, 305-318. https://doi.org/10.1002/9781119156949.ch17

[13] Arikan, F., Yilmaz, A., Arikan, O., Sa Yin, I. Gurun, M. and Yildirim, S.A. (2009) Space Weather Activities of IONOLAB Group: TEC Mapi. Geophysical Research Abstracts, 11, 5188.

[14] Turcotte, D.L. (1997) Fractal and Chaos in Geology and Geophysics. 2nd Edition, Cambridge University Press, Cambridge, UK.

[15] Hobara, Y., Lefeuvre, F., Parrot, M. and Molchanov, O.A. (2005) Low-Latitude Ionospheric Turbulence Observed by Aureol-3 Satellite. Annales Geophysicae, 23, 1259-1270. https://doi.org/10.5194/angeo-23-1259-2005

[16] Hayakawa, M. (2011) On the Fluctuation Spectra of Seismo-Electromagnetic Phenomena. Natural Hazards and Earth System Sciences, 11, 301-308. https://doi.org/10.5194/nhess-11-301-2011

[17] Hayakawa, M., Kasahara, Y., Nakamura, T., Hobara, Y., Rozhnoi, A., Solovieva, M., Molchanov, O.A. and Korepanov, V. (2011) Atmospheric Gravity Waves as a Possible Candidate for Seismo-Ionispheric Perturbations. Journal of Atmospheric Electricity, 32, 129-140.

[18] Liperovsky, V.A., Meister, C.-V., Liperovskaya, E.V., Vasileva, N.E. and Alimov, O. (2005). On Es-Spread Effects in the Ionosphere before Earthquakes. Natural Hazards and Earth System Sciences, 5, 9-62. https://doi.org/10.5194/nhess-5-59-2005 